\title{
La vida social de las cosas y los artefactos- documentos del Museo de Carmen de Patagones
}

The social life of things and artifacts-documents at Carmen de Patagones

Museum

\section{Julio Vezub}

\section{OpenEdition}

Journals

\section{Electronic version}

URL: http://journals.openedition.org/corpusarchivos/1083

DOI: 10.4000/corpusarchivos.1083

ISSN: 1853-8037

\section{Publisher}

Diego Escolar

\section{Electronic reference}

Julio Vezub, «La vida social de las cosas y los artefactos-documentos del Museo de Carmen de Patagones ", Corpus [En línea], Vol 2, No 1 | 2012, Publicado el 30 junio 2012, consultado el 22 abril 2019. URL : http://journals.openedition.org/corpusarchivos/1083 ; DOI : 10.4000/ corpusarchivos. 1083

This text was automatically generated on 22 April 2019.

Licencia Creative Commons: Atribución-NoComercial 2.5 Argentina (CC BY-NC 2.5 AR) 


\section{La vida social de las cosas y los artefactos-documentos del Museo de Carmen de Patagones}

The social life of things and artifacts-documents at Carmen de Patagones Museum

Julio Vezub

\section{EDITOR'S NOTE}

Fecha de recepción del original: 15/05/2012. Fecha de aceptación para publicación:

$18 / 06 / 2012$

1 En este número de Corpus inauguramos el "Espacio Archivos y Museos" con el anhelo de convertirlo en un canal de comunicación para que los archivos, bibliotecas y museos den a conocer de manera periódica sus fondos documentales, colecciones, catálogos y bases de datos.

2 También, para que informen los servicios que ofrecen a los investigadores y usuarios, la realización de muestras y exposiciones, paneles de debate y actividades, publicaciones, nuevos proyectos de valorización patrimonial, digitalización y sistematización de fuentes, etc.

3 Abrimos esta sección con la presentación del Museo Histórico Regional "Emma Nozzi" (MHREN) de Carmen de Patagones, no solamente por la amistad que nos une a los que hacemos Corpus con los colegas de allí, sino porque se trata especialmente de una institución emblemática por su política de puertas abiertas al público y a los estudiosos, atípica en comparación con otros museos y repositorios regionales en materia de desclasificación documental, crítica museológica y promoción de discusiones que conectan presente y pasado en dimensiones atentas a lo local, pero con impacto global. Muchas veces escuché hablar de "museos vivos" para aventar culpas o similitudes con los 
mausoleos y cementerios. Aunque en el MHREN nunca lo oí, este merecería perfectamente una caracterización como esa: si bien resulta difícil y hasta contradictorio por definición que un museo tenga vida, el "Emma Nozzi" tiene el aura del recinto del chamán, el que oficia de intermediario en la relación siempre inestable, precaria y amenazada de acechanzas entre los vivos y los muertos.

4 Frente al muelle de la ciudad bonaerense en Patagonia, a la vera del río que trae el agua desde los Andes, al pie de la barranca donde se asienta la aldea emplazada en 1779 en tierras del cacique Negro, el museo es el punto de condensación de los destellos de historicidad de las calles, chacras y edificios del enclave fronterizo, el nodo atlántico de la red sociopolítica que vinculaba Carmen de Patagones con Valdivia en el océano Pacífico por los caminos indígenas que atravesaban los pasos cordilleranos.

5 Los guías explican a los visitantes que el apéndice sureño de la provincia de Buenos Aires fue el resultado de las prerrogativas de los hacendados, que evitaron que sus propiedades entre los ríos Colorado y Negro quedaran incluidas a partir de 1878 dentro del Territorio Nacional de la Patagonia. Como consecuencia indirecta de ese autonomismo, el MHREN depende hoy en día del Banco de la Provincia de Buenos Aires, que tiene a su vez el Archivo y Museo Históricos “Dr. Arturo Jauretche” en plena city porteña, escasamente consultado por los especialistas de la historia indígena que harían hallazgos entre sus legajos bancarios. Si la institución crediticia más antigua de la Argentina tiene esta política de aliento del patrimonio histórico, mucho de la orientación del museo patagónico se debe a Jorge Bustos, historiador y director desde 1993, quien ha sabido actualizar lo mejor del legado de Emma Nozzi -la directora anterior desde la fundación en 1951-, conforme a los desafíos de la museología histórica contemporánea, más ligada a preguntas sociopolíticas perentorias que a los relatos míticos de la nación. Es precisamente en este giro donde el museo redefine sus tareas educativas y de preservación de la memoria, concebido como espacio de debates antes que de fijación de certezas.

Obviamente, otra motivación para elegir el MHREN en el debut de la sección "Archivos y Museos" es la riqueza y diversidad de sus colecciones. Cuando desde el Comité Editor de Corpus pensamos la revista como un archivo de la alteridad americana, el punto de apoyo de nuestra maquinación virtual fue la materialidad de repositorios como el de Carmen de Patagones. A decir verdad, nos inspiramos en la heterogeneidad tipológica, en la variedad de formatos y en la polifonía de fuentes que este museo despierta para nuestros afanes de desclasificación. De allí el uso del sintagma de Arjun Appadurai sobre la vida social de las cosas, para referirnos tanto a la historicidad de los objetos como a la objetivación de las historias que se narran a partir de los artefactos-docu- mentos.

7 Hemos seleccionado un par de artefactos-documentos del tesoro del MHREN por el modo en que a partir de los mismos se despliega un corpus heterogéneo. Se trata del original del "Arreglo entre el Cacique Foyel y el Gobierno de la República Argentina" (transcripto en el anexo de esta presentación), y del toki o clava ceremonial que el mismo Foyel le regalara al comandante Liborio Bernal cuando la firma del "Arreglo" en 1873. Ambos instrumentos fueron incorporados al archivo de Bernal para volver a Carmen de Patagones en momentos distintos. En el caso del toki a través de la donación reciente de los hijos de Liborio Justo ${ }^{1}$, hijo a su vez del presidente de la nación Agustín P. Justo (1932-1938) y nieto del comandante Bernal.

8 La documentación heredada de su abuelo materno es abundante en el MHREN; entre otros, se destacan los dos libros copiadores de notas de la comandancia militar, 
responsabilidad de Bernal entre 1874 y 1879. Estos libros, que poseen información sobre la diplomacia y las acciones de guerra con las jefaturas indígenas, fueron donados al museo por Liborio Justo. Sus páginas tienen estampado el ex libris de la biblioteca personal de este hijo díscolo de uno de los presidentes de la "Década Infame",cazador de ballenas en los mares del Sur, militante comunista y luego trotskista, reportero gráfico de la crisis de 1930 en Nueva York, quien durante la recepción que su padre dio al presidente Roosevelt gritó la consigna "Abajo el imperialismo yanqui". Escritor de novelas y ensayos que firmaba con el seudónimo de "Lobodón Garra", entre la obra de Justo ocupa un lugar importante A sangre y lanza (Garra 1969 ), texto que se nutre en profundidad del archivo del abuelo y que anticipa tempranamente los mejores análisis sobre la política indigenista del siglo XIX, introduciendo aspectos como el "Negocio Pacífico de Indios" que la producción académica recién estudiaría a partir de los años noventa.

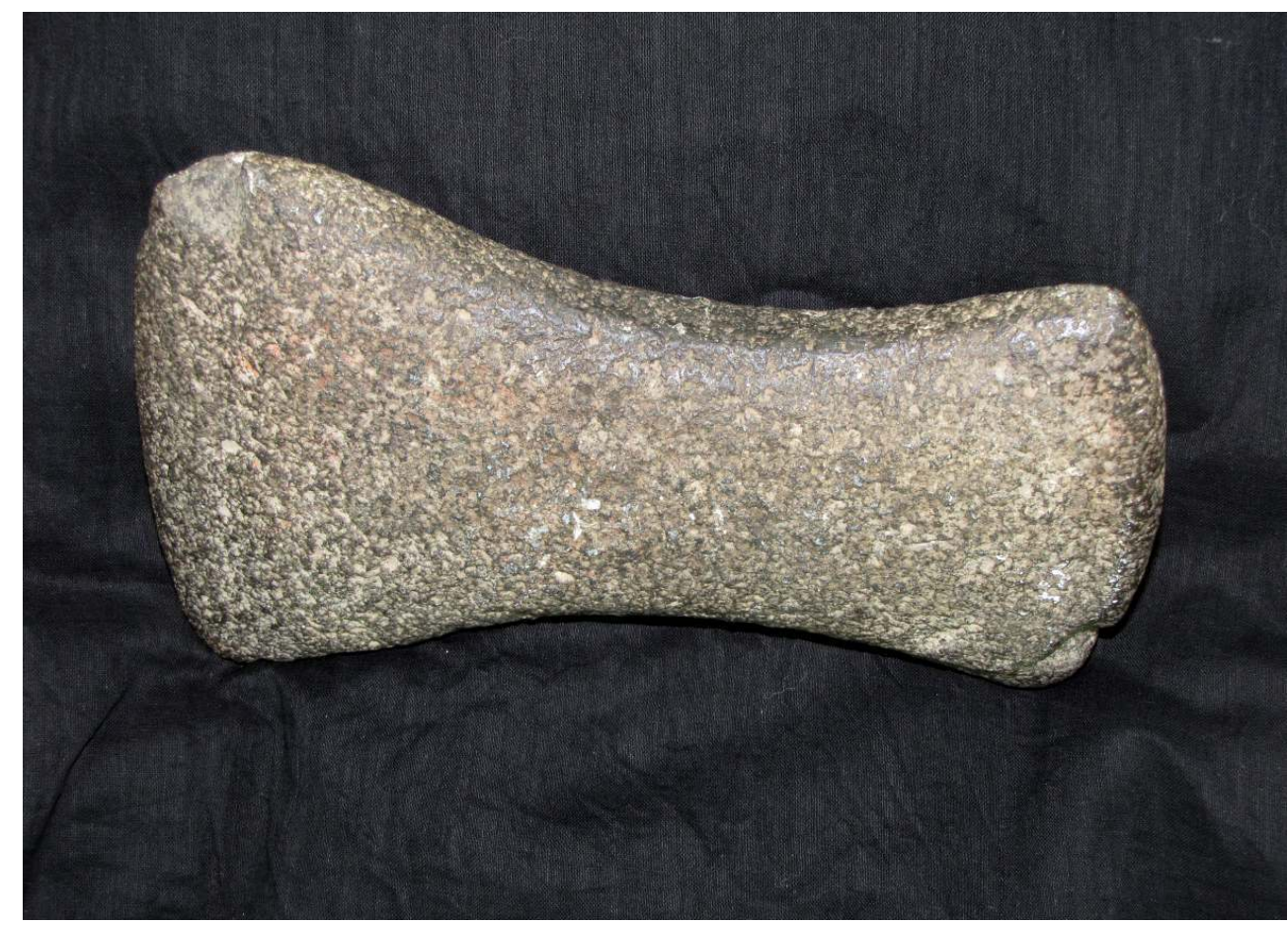

Figura 1: Toki de mando de Foyel. Colección MHREN, Carmen de Patagones.

Respecto del toki de Foyel, hacha trapezoidal de la que hay al menos un antecedente arqueológico en la meseta central de Río Negro (María Teresa Boschín, com. pers. Veáse la figura 1), los hijos de Liborio Justo saben por el relato paterno que el bisabuelo Bernal valoraba especialmente este objeto, el que conserva restos de pintura roja que impregnan la piedra, marcas de identidad y linaje, atributos del prestigio de Foyel entre la gente del interior patagónico septentrional y la cordillera desde Chubut hasta Neuquén. La valoración que Bernal tenía de este regalo superaba el coleccionismo de rarezas y la curiosidad del anticuario: el comandante sabía perfectamente de qué se trataba el don de Foyel, entendía que el hacha con su larga historia, además de fetiche del mando, era la materialización del "Arreglo" o su contradocumento.

10 Mediante el papel y la piedra, este registro simultáneo inscribe la alianza entre Foyel y Bernal. Una alianza que no se prolongó demasiado en el tiempo y que ya insinuaba su crisis en la degradación del "tratado" a "arreglo", tal como se ha señalado en los estudios que historiaron los acuerdos entre las autoridades argentinas e indígenas de la segunda mitad del siglo XIX. Registro escritural doble, que aunque Foyel "no supiera firmar", 
quedó impreso de su puño y letra en el trazo firme de tinta: "Hizo la señal de la cruz", aclara el notario para destacar la teatralidad del acto (Figura 2). ${ }^{2}$ De esta manera, desde el MHREN se interpelan los archivos intertextuales de Foyel-Bernal o de Bernal-Foyel. Archivos que se multiplican como rizomas, que incluyen la proliferación de topónimos que inscriben el nombre del cacique en el oeste de Chubut y Río Negro, los misterios sobre el lugar de su entierro y la aparición del fantasma (Masotta, 2009), o del mapa catastral del Territorio de Río Negro donde están dibujados los límites de la "Estancia Vieja" de Liborio Bernal sobre el lago Nahuel Huapí, el territorio de Foyel desde donde Bernal continuó con el comercio ganadero hacia Chile que antes controlaban los ulmenes o grandes hombres mapuches y tehuelches. ${ }^{3}$

11 ¿La mala conciencia por la alianza rota justifica el valor que el comandante le daba a la clava de piedra que aseguraba el pacto del cacique con el Estado? No hay archivo para responderlo y solo podemos imaginarlo históricamente. Pero sí conocemos el valor del MHREN como consignatario de este corpus documental de Foyel- Bernal o Bernal-Foyel, en el sentido que Derrida definió la consignación de los archivos, como una reunión de signos donde se integran funciones topológicas y nomológicas (Derrida 1997). Solo que los arcontes del museo fundado por Emma Nozzi habilitan un lugar pero varias interpretaciones para la documentación, también infinitas organizaciones virtuales de esta, logrando mediante su política que el archivo estatal se haga verdaderamente público, abandonando el régimen del secreto y la tutela del pasado al que por definición todo museo estaba destinado.

Figura 2: Facsímil de la última foja del "Arreglo entre el Cacique Fo- yel y el Gobierno de la República Argentina". Documento No 8157, Archivo del MHREN, Carmen de Patagones.

Por último, con estos materiales y reflexiones esperamos estimular a otros museos y repositorios para difundir sus colecciones e historias, políticas y propuestas de interacción con los estudiosos y el público en general. Deseamos también que cada participación institucional se reitere o tenga continuidad en los números futuros de Corpus, promoviendo la generación de enlaces con los respectivos sitios de Internet y fomentando proyectos colaborativos que vinculen la revista con las instituciones y a éstas entre sí.

\section{Anexo}

Arreglo entre el Cacique Foyel y el Gobierno de la República Argentina

El Cacique Foyel deseando establecer una paz sólida y duradera con el Gobierno de la República Argentina y deseando este prestar al dicho Cacique todo el apoyo y protección que le sean posibles de manera que todo redunde a favor de la seguridad y bien del país en general; han convenido ambos en apuntar y celebrar el arreglo comprendido en los artículos siguientes, que se prometen solemnemente y se obligan a cumplir con toda exactitud y lealtad.

Art. 1.- La tribu e indiada del Cacique Foyel y los amigos de él podrán venir libremente a comerciar en el Pueblo del Carmen y en cualquier otro punto de la República Argentina, y las personas como también las amistades y efectos que conduzcan a que lleguen a asegurar legítimamente serán completamente respetados y protegidos. De igual modo todo habitante de la República Argentina que quiera ir a comerciar con dicha tribu e indiadas, podrá hacerlo libremente y su persona como también los animales y efectos que conduzcan o que lleguen a adquirir allí legítimamente serán "completamente respetados y protegidos. 
Art. 2.- Habiendo determinado al Gobierno de la República Argentina explorar el río Negro en todo su curso el Cacique Foyel se compromete a prestar todos los auxilios que le sean posibles, los que serán debidamente remunerados y pagados por el Gobierno.

Art. 3.- Si el Gobierno de la República Argentina determinara ocupar algún punto militar en la costa del río Negro el Cacique Foyel se compromete a prestar todos los auxilios que sean necesarios.

Art. 4.- El Cacique Foyel se obliga a estar siempre pronto con su indiada para proteger y apoyar la defensa de Patagones, obrando a las órdenes del Comandante de este punto y seguir las instrucciones que de él recibiere.

Art. 5.- Queda obligado el Cacique Foyel a transmitir al Comandante de Patagones y a cuantas autoridades del Gobierno le sea posible toda noticia que adquiera a cerca de intentos de invasión o movimiento de indios enemigos.

Art.6.- El Cacique Foyel reconoce al Cacique Don Miguel Linares por amigo del Gobierno y Jefe de los campos y serán indios enemigos del Cacique Foyel todos los indios que sean enemigos del Gobierno y si fuese atacado $u$ hostilizado por algunos de ellos recibirá de las fuerzas y de las autoridades del Gobierno toda la protección y auxilio que fuesen posibles según sean las circunstancias del caso.

Art.7.- En caso que el Gobierno resolviere atacar o expedicionar contra indios enemigos está obligado el Cacique Foyel a presentarse en compañía de todos sus indios, debiendo obrar en todo con sujeción a las órdenes que le comunique el Jefe o autoridad que el Gobierno designe al efecto.

Art.8.- Llegado que sea el caso del artículo anterior el Cacique Foyel, los Capitanes y Soldados de que se compone su tribu recibirá mientras dure la campaña los indios que están fijados para los indígenas y serán además alimentados por cuenta del Gobierno para todo lo cual serán revistados cuando se disponga.

Art.9.- El Gobierno se obliga a darle anualmente cien yeguas al corte, ciento cincuenta libras azúcar, ciento cincuenta libras yerba, ciento cincuenta libras fariña, setenta y cinco libras tabaco negro en rama, una resma papel de hilo, un vestuario completo para el Cacique y tres para los capitanes. Y en fe de todo lo que queda pactado se firmará dos ejemplares de un tenor que serán firmados por el Cacique Foyel y por el Teniente Coronel, Don Liborio Bernal, Comisionado por el Superior Gobierno para formular tratados con los indios: habiendo concurrido como testigos el señor Don Benito Crespo, Don José Atkins y el Subteniente Don Juan J. Breciano. En Patagones a diez de julio de mil ochocientos setenta y tres.

El Cacique Foyel por no saber firmar hizo la señal de la cruz

Liborio Bernal

Testigo José Atkins

Testigo Benito Crespo

Juan J. Breciano 


\section{BIBLIOGRAPHY}

Derrida, J. (1997). Mal de archivo. Una impresión freudiana. Madrid: Editorial Trotta

Garra, L. (1969). A sangre y lanza. Buenos Aires: Ediciones Anaconda

Masotta, C. (2009). El fantasma del cacique Foyel. Apariciones y apropiaciones entre la toponimia y el mito. Actas de las XII Jornadas Interescuelas / Departamentos de Historia. Bariloche: Universidad Nacional del Comahue

\section{NOTES}

1. Los donantes del toki de Foyel son Mónica, Ana Victoria y Pablo Justo Dimenstdtein, hijos de Liborio Justo o "Lobodón Garra".

2. Se destaca la firma de Foyel con la señal de la cruz.

3. Una copia original del mapa "Territorio del Río Negro - Tierras afectadas a la ley 5559 se conserva en el Museo de la Patagonia, dependiente de la Dirección Nacional de Parques Nacionales en Bariloche. Agradezco a Natalia Cano el facsímil del mapa y el dato sobre el negocio ganadero que continuó Bernal después de la ocupación del territorio.

\section{ABSTRACTS}

With this paper we start a new section at Corpus - Archivos virtuales de la alteridad americana, called "Espacio Archivos y Museos" [Space Archives and Museums]. It also presents the institution with which the section is opened, i.e. the Regional History Museum "Emma Nozzi" (MHREN) at Carmen de Patagones, province of Buenos Aires. It describes the characteristics of the museum and justifies the choice to start this channel of communication and sharing among archives, libraries and museums. Finally, it introduces the reader with the richness of MHREN collections through the comment on two of their artifacts-documents: chief Foyel's toki or staff of command and the agreement he signed with Major Liborio Bernal on behalf of Argentina's government in 1873.

Esta nota da apertura a la nueva sección de la revista Corpus - Archivos virtuales de la alteridad americana, denominada "Espacio Archivos y Museos". Se presenta también la institución con la cual se inaugura la sección, el Museo Histórico Regional "Emma Nozzi” (MHREN) de Carmen de Patagones, provincia de BuenosAires. Se describen las características de dicho museo y se justifica su elección para iniciar este canal de comunicación y difusión entre archivos, bibliotecas y museos. Por último, se introduce al lector en la riqueza de las colecciones del MHREN mediante el comentario sobre dos de sus artefactos-documentos, el toki o clava de mando del cacique Foyel y el acuerdo que éste firmó con el comandante Liborio Bernal en representación del gobierno argentino en 1873. 
INDEX

Palabras claves: archivo, museo, documento, historia

Keywords: archive, museum, document, history

\section{AUTHOR}

JULIO VEZUB

Centro Nacional Patagónico, Consejo Nacional de Investigaciones Científicas y Técnicas, Argentina.

Correo electrónico: vezub@cenpat.edu.ar 